\title{
Conceptual spatio-temporal data modelling and land use change
}

\author{
L. A. Beser de Deus ${ }^{1}$, L. F. C. F. Silva ${ }^{2}$ \& M. A. V. Freitas ${ }^{1}$ \\ ${ }^{I}$ Federal University of Rio de Janeiro, Brazil \\ ${ }^{2}$ Military Institute of Engineering, Brazil
}

\begin{abstract}
Space and time are fundamental elements that enable us to understand the phenomena evolution. There are several applications and studies demands that require both concepts: the development and the evolution of areas, the occupation and land use, the search and research for elements and the geographic features modified by the landscape, landscape alterations caused by earthworks, rectification of the hydrography, city planning, etc. Space-time studies are essential to establish the understanding of such evident integration of these two terms, frequently analyzed in a disconnected and isolated way. Nowadays, most of the GIS - Geographic Information Systems - available consider the entities representation in only one instant of time, usually the present. The main subject on the association of geographical data with time is not due to its modification or update, but for the possibility to register past states. Moreover, specifically about GIS, to use it as a technological instrument for accomplishment of space-time analysis, and not only "space" as it is being used thoroughly. This kind of analysis is only possible within the implementation of spatio-temporal models that consider not only apparent entities and its geometrical shapes, but its processes and transformations. In this context, a bibliographic review in the scientific literature was made to establish the state of art on the temporal characteristics that allowed the structuring of a conceptual space-time model using geographical and historical data for structuring of a TGIS (Temporal GIS). TGIS will support studies aimed at understanding the changes of land use, transformations of public spaces in urban areas. This can be applied to a project which has been developed at the Military Institute of Engineering in a park called Campo de Santana (Guanabara Bay Basin), located on Republic Square,
\end{abstract}


downtown Rio de Janeiro (Brazil), showing its appreciation and depreciation processes throughout its history.

Keywords: GIS, conceptual model, spatio-temporal applications, land use change, city planning.

\section{Introduction}

Some studies need temporary aspects for analyses accomplishment and inferences about a specific phenomenon. These studies can be done through tools that are useful when a decision has to be taken, such as, the GIS (Geographic Information Systems) that have been conceived as analysis, planning and decision tools about the geographical space. According to Thom and Fornari (page 13) [1], "time is an essential concept for the understanding and modelling of space phenomena in several applications, such as: biophysical sciences, epidemic researches, political, social and economic sciences and several applications of real time for management and planning."

The use of a space-time model in GIS increases its capacity of analysis, facilitating the study of the evolution of geographical phenomena. Besides, there is other more specific applicability that can be identified when temporal dimension is incorporated to GIS, for instance, forest resources management, urban and regional planning, transportation, and so on.

However, nowadays, the majority of available GIS consider the representation of entities as if the world was only a particular moment in time, which is usually the present. Medeiros and Botelho (page 1) [2] mention that "in spite of the fact that GIS are able to analyse a great amount of data in an integrated and flexible way, they are still unable to represent the changes that happen along the time, assuming a limited and an instantaneous vision of the reality they model."

Since the beginning of the nineties, studies were done about the need of insertion of temporal information in GIS. In Langran [3], it is possible to analyse some technical requirements for the insertion of time in GIS. In relation to time representation, what can be taken to the understanding of this "representation" in GIS are the cartographic notions associated to space-time representations, as mentioned by Vasiliev [4] and Peuquet [5, 6] and again by Langran [3] about the cartographic time. So, the conceptual and practical construction of a Temporal GIS also could be supported by studies about visualization of the aspects of space-time phenomena, focusing aspects about simbology in space-time maps and data presentation using visualization aspects or cartographic animation as a resource, suggested by some authors, for example, Visvaligam [7] and Peterson [8].

However, currently, there are still several difficulties on working with temporary phenomena, specifically concerning the modelling, storage, spacetemporal analysis and the representation of geographical data. Peuquet (page 101) [5] mentions that still remains a lot to be done before a temporal geographic information system can truly be accomplished. So to speak, the best 
thing to be done would be to join temporary dimension, even if in a conceptual way, to this instrument.

The importance of the study about time in GIS is reflected on the capacity that this instrument will have to guide a decision making in advance. It will also provide a dynamic space understanding. Through space-time models, considering the knowledge of processes and flows, it will be possible to subsidize the planning, management and decision on territory, producing diagnoses or even prognoses that the space-time analyses allow.

\section{Goals}

Propose a conceptual space-time model using geographical and historical data for structuring of a Temporal Geographic Information System (TGIS), that is also known as Historical Geographic Information System (HGIS) according to its application. TGIS or HGIS will support studies aimed at understanding the changes of land use, transformations and / or development of public spaces in urban areas. Thus, this can be applied to a project which has been developed at the Military Institute of Engineering in a park called Campo de Santana, located on Republic Square, downtown Rio de Janeiro, showing its appreciation and depreciation processes throughout its history.

\section{Spatio-temporal conceptual models for GIS}

Models are simplified representations of reality, and this process of representation of reality involves abstractions, generalizations and approximations due to the complexity of real world.

According to Corrêa [9], there are several ways to express the process of modelling or the solution of a real world problem. One of them, according to Elmasri and Navathe [10], is possible through the stages of a database project that can be associated with different types of models.

Within this context, there are the conceptual models that provide concepts such as entities, attributes and relationships that are close to the way many users perceive data [9]. A conceptual model should allow a direct mapping between what is perceived in the real world and its computational representation and, also, should be free from the constraints on implementation. Therefore, as Pinheiro and Fornari [11] have already discussed, the mapping of real-world information to a computing environment is achieved through the process of conceptual data modelling. According to Rocha [12], in the conceptual phase of modelling, it is important to express the reality graphically. However, as the reality of a TGIS involves the time dimension and the space dimension, there is a lot of information to be modelled, which tends to make the data model rather complex. The use of symbols (called stereotypes or pictograms) is an interesting way to introduce these dimensions visually, allowing a more complete symbolic representation.

Recently, several conceptual data models have been presented. They try to contemplate the spatial and temporal aspects of data, depending on the purpose 
for which it is intended. However, none did become consensus and they are widely used by designers of GIS software. Some existing models for spatiotemporal GIS can be cited: GeoOOA, Modul-R, MADS, OOTGIS and STER. Especially about the Modul-R, this will be detailed below.

\subsection{Perceptory (MODUL-R)}

Caron and Bédard [13] describe an extension of the ER model (EntityRelationship) for urban geographic applications, called Modul-R Formalism (The term MODUL-R is unambiguous: "MODUL" implies a modular modelling structure while " $R$ " signifies an integrated modelling of reality), to address the following requirements: spatial reference, time reference, database complexity and dichotomy between data and processes. In addition, the Modul- $\mathrm{R}$ is a conceptual level formalism adopted for the database space-time. The main feature of Modul-R Formalism is its ability to propose, in a unified way, the modelling of complex references, space and time through the use of modules for each context of the project $[1,12,14]$.

The project was initially developed by École Polytechnique Fedérale of Lausanne and Laval University and then it eventually evolved into an objectoriented approach (OO) and the use of the UML formalism (Unified Modelling Language) [15]. It may become the Perceptory $[1,12,14]$. Thus, the Perceptory is the evolution of OO Modul-R.

UML is a modelling language and not a method. Vieira [16] cites that the basic difference between a language and a method is that the method indicates "do's", "how to do", "why do" and "when do". Therefore, the method presents direct implications with a particular organization in terms of objectives to be achieved.

On the other hand, the language consists of notation and rules of semantics and syntax to express the models that comprise the method (Erikson and Penker in Vieira) [16].

Nowadays, the project Perceptory is maintained by Laval University that has been developing a visual tool for modelling of applications in addition to a model of spatio-temporal data.

\subsection{The choice of perceptory}

To this extent, the project Perceptory did become suitable for the construction of the proposed model for its urban application and the possibility of space-time representation. For the representation and understanding of the model, the UML formalism was and is essential because most of the model uses this language as formal definition. The study of UML is presented in a very dense and complex way. Moreover, more information about the representation language for modelling UML (Unified Modelling Language), notations and rules, which can aid the understanding of the model, are found in Rumbauch et al. [17], Furlan [18], Heuser [19], Vieira [16] and Bédard [20]. 


\subsection{Perceptory design in practice}

The modelling of spatial elements and space-time in Perceptory is possible due to the use of UML extension called stereotypes or pictograms. All information about the structure of Perceptory, such as, classes, attributes, relationships, the association (characterized by a semantic relation), aggregation (relation expressed by the verb to have), the composition (relation expressed by the verb to compose), the generalization, specialization, notes, packages and others can be viewed in Bédard [20]. Here the focus will be on the temporal or spatialtemporal and on some aspects associated with them.

There are two basic temporal concepts in Perceptory: existence and evolution rules. The concept of existence is used in the object and sets the time of its life. Its boundaries are birth and death of the object. The concept of evolution is applicable when the object state changes. The evolution can be characterized descriptive when considering the exchange of the attributes values of the object or of the space type when the values of exchange are maintained at the level of location and shape of the object mapping $[1,12,20]$.

Concerning the issue, a set of stereotypes (pictograms) was created: spatial (to compose the geometries of the modelled objects - spatial form of objects), temporal to compose the temporalities (regarding the existence and evolution the latter combined with spatial pictograms) of the modelled objects (Figure 1).

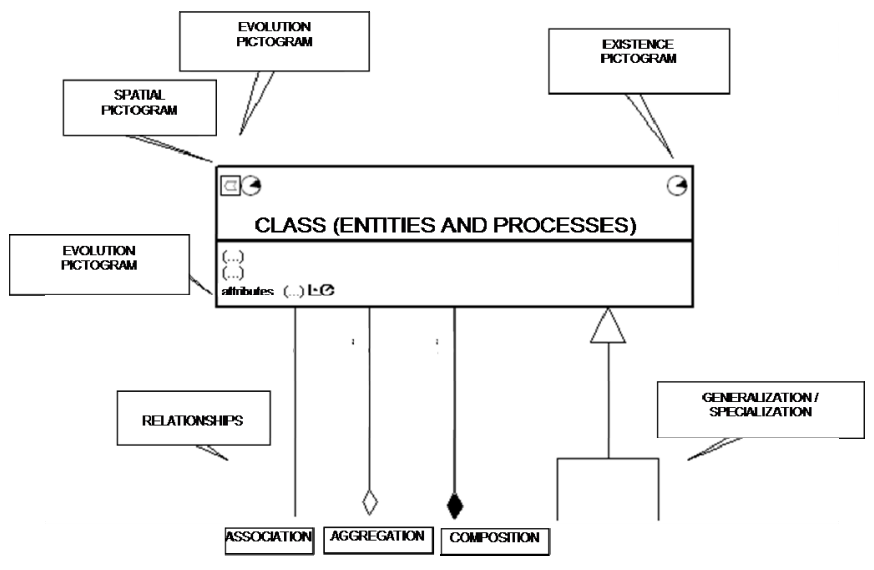

Figure 1: Positional semantics (Perceptory).

\section{Case study using Perceptory}

The present study of a proposed case uses the Perceptory as a tool for structuring the conceptual model. This case study may intend a space-time application of this instrument within an urban area in order to consolidate the first stage of a TGIS building that, in this case, seeks the building of a geographic-historic conceptual model. 


\subsection{Study area and location}

Considering temporal aspects, the area to be modelled is called Campo de Santana, located on Republic Square, downtown Rio de Janeiro. The purpose of this choice may be the understanding of its spatial dynamic in different time frames. Campo de Santana is an urban green area [21] that, within a conceptual hierarchy, is fitted as a public space. Figure 2 may illustrate the changes that occurred in this area over 500 years approximately.

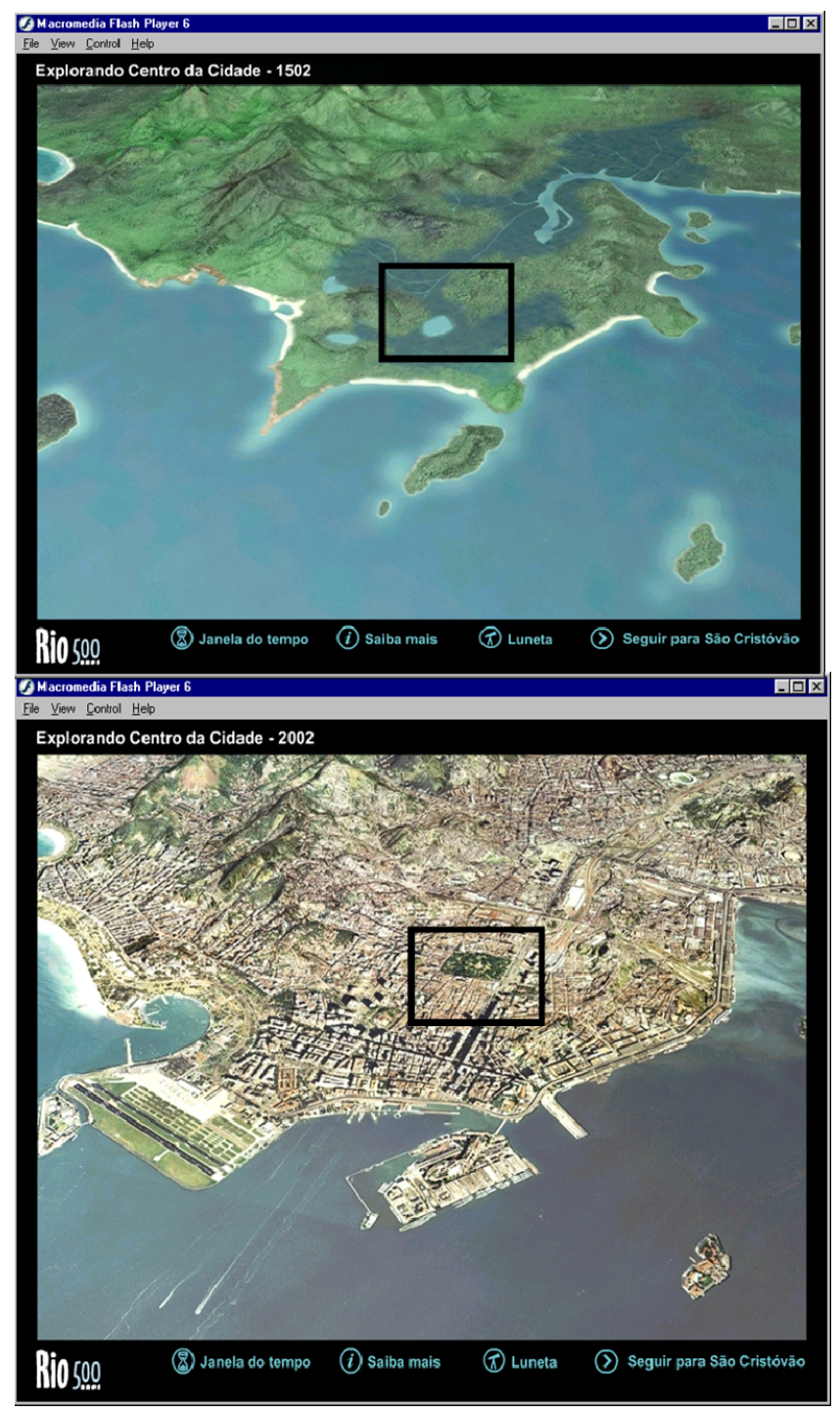

Figure 2: $\quad$ The evolution of Campo de Santana (1502-2002) [22]. 


\subsection{Problem}

The conceptual model schema will focus on aspects of social and spatial appreciation and depreciation over the history of the public space of Campo de Santana. This area in particular is regarded as the centre of Imperial Brazil (Nineteenth Century), where the most important buildings of this political season were located. And still today, with some important buildings in its vicinity, for example, Duque de Caxias Palace and the house where Marshal Deodoro da Fonseca lived. During the twentieth century, this centre was losing relative position simultaneously with the beginning of a process of degradation of public property, invasions of certain buildings and the devaluation of the spatial area.

In summary, it deals with a spatial area full of historical information, where its spatial dynamic was modified in specific and not identified time intervals. From this scenario, some questions arise and they can be answered or addressed by a TGIS. Consequently, it may be possible to observe the idea of movement and process in all the questions that are about the study area and will be presented below:

- How and when was the degradation of public property with the loss of the relative position of Campo de Santana (historical periods)?

- Where and when did the uses that valued the area go?

- When is specifically the loss of centrality?

- How did the dynamic of objects with their actions happen?

- What are the periods of the highest and the lowest value of this public space?

- How is it possible to get the current scenario of the Field and the changes that marked this area?

Then, it seems to be appropriate to choose the area to conduct the conceptual modelling, considering spatial and temporal aspects. Most of the information that supported the process of conceptual modelling of Campo de Santana was taken from a diagnosis [23] on the study area. In the diagnosis, it was possible to establish restrictions in order to isolate the problem (phase of reality model) and, also, to identify various agents and events that marked the history of this public space, for instance, changes of toponomy, historical landscape, changes in the physical environment, socioeconomics, cultural aspects, management of public property and so on and so forth. This diagnosis did enable the cataloguing of over one hundred events that happened in the study area throughout its history (in the last five hundred years).

\subsection{Modelling considerations}

This section will propose some considerations about the case study that did guide the construction of the conceptual model diagram inside the Perceptory, and therefore, they must be submitted:

- Navigability: it can be mentioned that the processes that occur in space do not act only in one direction, acting as reflection and condition, so bidirectional. 
- Temporality: the objects and the actions (man) of Campo de Santana are gathered in a logic that is, at the same time, the logic of past history and the logic of today. Then, it was necessary to instantiate not only bygone events as well as current situations to characterize the temporality of the model.

- Inseparability: the geographical space, stage (resulting / determinant) of the historical events of Campo de Santana, may be conceptualized as a system of entities and a system of actions. It is worthy to highlight that entities and actions are inseparable. A separate analysis of these systems can mask the study of the proposed space-time [24].

- Complexity: each modelled object is itself a system operating systematically. Examples similar to the supermarket, the shopping centre or a built-up area may prove the existence of complex and systemic objects that connect themselves to other systems [24].

- $\underline{\text { Scale: }}$ the concerned model portrays the reality in an intra-urban scale of a public space. However, just as some temporal events must be linked to other temporalities, mostly, the fact that triggered particular case happened due to previous cases. A similar fact also occurs with space. Then, the social and spatial dynamic depends not only on internal agents of the field (inner scale), but also on external agents (outer scale) which interfere more or less intensely in the spatial organization of the concerned area. These external agents can be located very close to the Field, for example, the case of adjacent local trade or, more distant, a political agent of the federal power sphere. In this case, proximity does not define the intensity of the agent's action.

- Space and its agents: public space, which is based on this case study, is the accessible place to all citizens and where an audience gathers: political / urban, cultural (religious), economic, social, historical, environmental and geographic agents that constitute a society. And so, they characterize the present agents of the model.

- Classes: in the modelling, the classes do not only represent entities of objects, but fundamentally, actions. In other words, the given focus refers to the processes or to process modelling.

- Restrictions: The restrictions allow an approximation to reality. When Santos [24] states that the categories of space analysis are disjunctive, he presupposes that any restriction might be applied to them. These restrictions are not visible in the diagram, but rather inserted into the conceptual model within the Perceptory. As a resource, text notes were used to indicate the presence of restriction.

- Attributes: the term "attributes (...)" means that they are not complete for that class or possibility to enter any more piece of information. 


\section{Proposed conceptual model}

\subsection{Presentation of proposed conceptual model}

Below (Figure 3), part of the STS-CAMPO DE SANTANA (Spatio-Temporal Schema of Campo de Santana Park) may be shown and the suggested conceptual model can be verified in a preliminary way. It is entitled Conceptual SpatioTemporal Model of Appreciation and Devaluation of Campo de Santana to be used in TGIS. This was built in Perceptory (Version 2003 - Available freeware version in Bédard) [20] running on Microsoft Visio Standard 2002 (Trial version of 30 days).

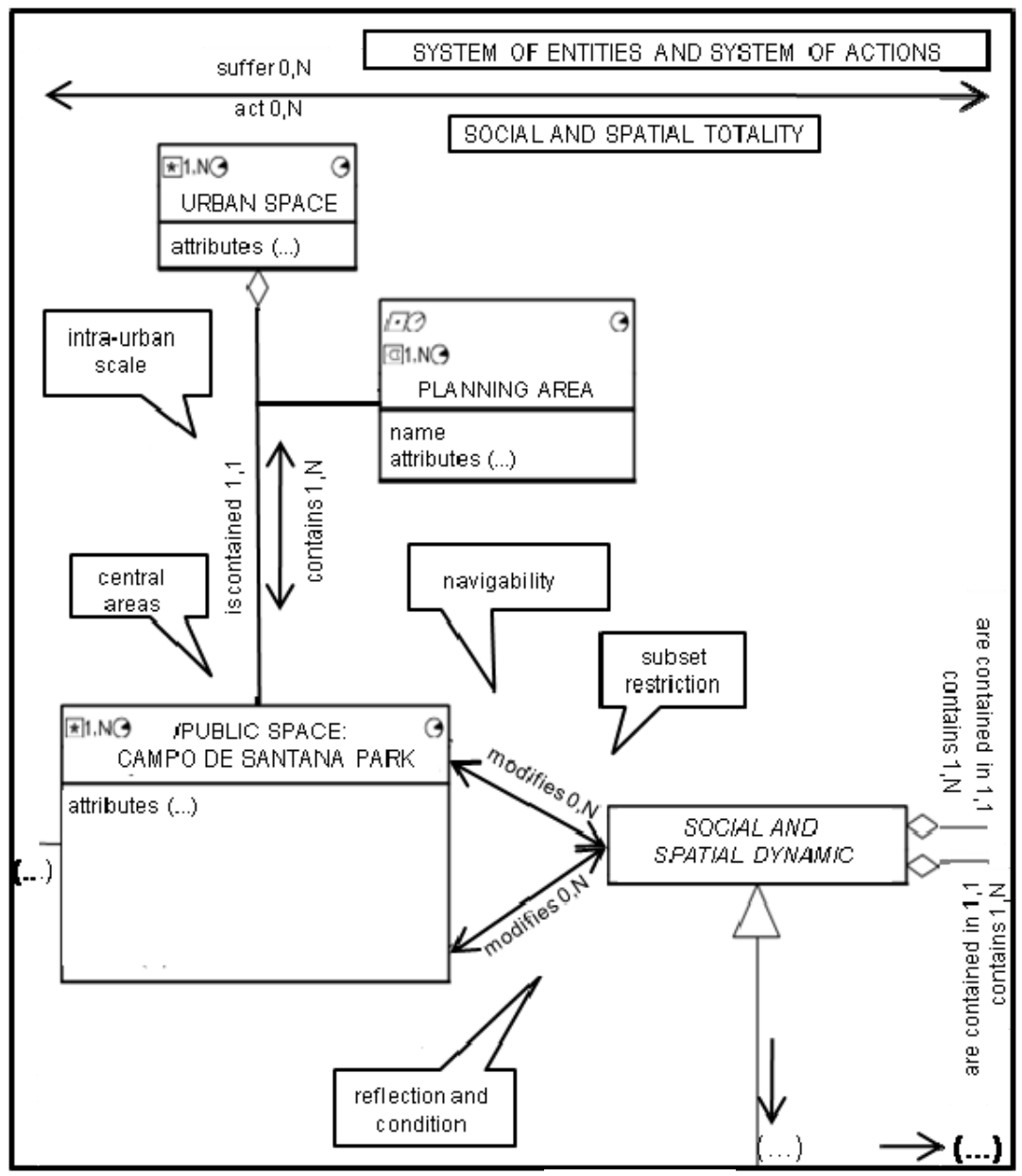

Figure 3: $\quad$ Part of the STS - Campo de Santana. 


\subsection{Description of proposed conceptual model}

As it was evidenced, Perceptory is a tool that consists of a palette of drawings manufacturers and, also, a data dictionary implemented in Microsoft Access system. Perceptory has a utility to generate automatically the database code skeleton for commercial GIS and universal servers. Thus, it is possible generate, specifically, a skeleton code for the Oracle 8i DBMS (Database Management System) [25]. Perceptory uses the terminology of UML and standards ISOTC211-19107 Geographic Information - Spatial Schema and ISOTC21119109 Geographic Information - Temporal Schema to define the geometries and temporalities.

As a result, the project Perceptory, that is the basis of the proposed conceptual model, generated a file extension $m d b$ (Microsoft Access) that refers to a meta-model (using a metadata structure), responsible for documentation and description of the elements used in the model, through a data dictionary. In this, all the elements of the conceptual model are described from a table structure, where there are classes, attributes, relationships, references and semantics of the produced diagram. Thus, there is the description of the mentioned components in the model explicitly and implicitly $[1,12,20]$.

Thus, we can compute, in a quantitative manner, the number of classes, relationships and attributes, and also the existing interfaces between them that are described too. It could be mentioned that there are about 80 classes, 160 relationships and 174 attributes, showing the amount of data to be worked. Qualitatively, the classes refer to objects and processes (justifying the temporal theme) while the attributes refer to characteristics, which are also subject to space-time change, specified in the model. Finally, the relationships are also subject to changes. These, to be represented "temporally", must be transformed into classes to facilitate the representation of the temporal symbol.

\section{Final considerations}

The reality of TGIS presents aspects of time and space and it involves a great number of data that must be considered in an integrated way in the spatiotemporal modelling, making this process and the created product complex. A proposal given by Rocha [12] is the use of stereotypes or pictograms to simplify the space-time modelled reality. Then, in order to support spatio-temporal aspect, a data model should show buildings indicating where, in the class diagram, these aspects can be captured. The Perceptory allows inclusion, specifically, of the temporal dimension in various levels, such as, class, attribute and relationships since these three principal dimensions express in different levels of representation of the modelled reality and the time is manifested in each one of them.

The construction phase of the Conceptual Spatio-Temporal Model introduced important concepts for the conceptual temporal modelling of data. Besides, it can identify the elements in a GIS that may be possible to "timing" and as this one should be represented. Spatial, temporal and spatio-temporal stereotypes have 
been described allowing that, in conceptual modelling of data, it could be possible to identify which represented elements may have or not the temporal capacity. Through this solution, it was possible to facilitate the visualization, allowing an identification of temporal elements in an easy, direct, concise and clear way. Thus, in conclusion, it may be considered that more theoretical and practical studies are needed, involving the project Perceptory objectively, in order to continue this project, which has only started, to proceed with the construction of a TGIS.

There is another criticism focused on analysis and generated products, in this case, by a TGIS. It is worthy to mention that models, specifically space-time, may model and reduce the reality. Moreover, they can act as advisors of the performed studies and projects. However, it is not recommended to consider these models as faithful portraits of reality, or totals. Since this is subjective and, in some cases, unique and too complex. Do not forget that the initial process of modelling is the perception of the fact. It becomes the phenomenon, by the researcher, for which he observed epistemologically with categories of predetermined analysis. Braudel (p. 37) [26] states about the question of models that "it is not against them, but against the use people make of them, believed that they are allowed to do."

\section{References}

[1] Thom, L. H. \& Fornari, M. R. Estudo de banco de dados temporais espaciais. Trabalho para Disciplina CMP 161. Sistemas de Informação Geográfica. Prof. Dr. Cirano Iochpe. UFRGS, 2000.

[2] Medeiros, C. B. \& Botelho, M. A. Tratamento do Tempo em SIG. GIS Brasil 96, 1996. p. 534-544.

[3] Langran, G. Time in Geographic Information Systems. London/ Washington, DC: Taylor \& Francis, 1993. 189p

[4] Vasiliev, I. R. Mapping Time. In.: Cartographica, monography 49, maio, 1997.

[5] Peuquet, D. Time in GIS and geographical databases. In: Geographical Information Systems: Principles, Techniques, Management and Applications. P. A. Longley, M. F. Goodchild, D. J. Maguire, D. W. Rhind, eds. New York: Wiley, 1999. p. 91-103.

[6] Peuquet, D. Representations of Space and Time. New York: Guilford Publications, 2002.

[7] Visvaligam, M. Visualisation in GIS, Cartography and VISC. In.: Visualization in Geographical Information Systems. Eds.: Hearnshaw, H. M.; Unwin, D. Wiley, cap. 3, 1994. p. 18-25.

[8] Peterson, M. P. Interactive and Animated Cartography. Prentice Hall: New Jersey, 1995. 257p.

[9] Corrêa, D. C. Sistema de Informações Geográficas na Mobilização Científica e Tecnológica da Força Terrestre. Rio de Janeiro: IME. Dissertação de Mestrado, 2000. 
[10] Elmasri, R.; Navathe, S.B. Fundamentals of Database Systems, Second Edition. Addison Wesley, 1994. pp. 873.

[11] Pinheiro, S. F.; Fornari, M. R. Implementação de um Modelo Conceitual Temporal e Espacial Utilizando o SGBD Oracle. ULBRA. http:/www.ulbra.tche.br/download/documentos/publicacoes/fornariseminco-2002.pdf. [capturado em 2010].

[12] Rocha, L. V. Geo-Frame-T: Um Framework Conceitual Temporal para Aplicações de sistemas de Informação Geográfica. Dissertação de Mestrado. Porto Alegre: PPGC da UFRGS, 2001.

[13] Caron, C. \& Bédard, Y. Extending the Individual Formalism More Complete Modeling of Urban Spatially Referenced Data. Computers, Environment and Urban Systems, v.1, 1993. p. 337-346.

[14] Rocha, L. V. Aspectos Temporais em Sistemas de Informações. Porto Alegre: CPGC da UFRGS, 2000. Trabalho Individual. 67p.

[15] Booch, G. et al. The Unified Modeling Language User Guide. Menlo Park: Addison-Wesley, 1999.

[16] Vieira, A. J. B. Modelagem espaço-temporal de fenômenos topográficos. Plano de Tese. Curitiba: UFPR, 2001.

[17] Rumbauch, J. et al. Modelagem e Projetos Baseados em Objetos. Rio de Janeiro: Campus, 1994.

[18] Furlan, J. D. Modelagem de Objetos através da UML - the Unified Modeling Language. São Paulo: Makron Books, 1998.

[19] Heuser, C. A. Projeto de Banco de Dados. 4. ed. Instituto de Informática da UFRGS. Editora Sagra Luzzato, 2001. 203p.

[20] Bédard, Y. Welcome on the Website of Perceptory. http://sirs.scg.ulaval.ca/ perceptory/enewindex.asp [capturado em 2010].

[21] Carvalho, P. F. Repensando as áreas verdes urbanas. In.: Território \& Cidadania, ano III, número 2, dezembro, 2003.

[22] IPP. Rio 500 anos - Uma janela no tempo sobre a cidade maravilhosa. Rio de Janeiro: Prefeitura da Cidade do Rio de Janeiro, 2002. CD ROM.

[23] Beser de Deus, L. A. Evolução da Paisagem do Campo de Santana Centro/RJ - Através de Representações Cartográficas. Estágio de Campo III. Rio de Janeiro: UFRJ, 2003.

[24] Santos, M. The Nature of Space. São Paulo: Hucitec, 1996.

[25] Lisboa Filho, J. \& Pereira, M. Desenvolvimento de uma ferramenta CASE para o modelo UML-GeoFrame com suporte para padrões de análise. In: Anais do Simposio Brasileiro de Geoinformática (GEOINFO), 4, CaxamúMG. Belo Horizonte: SBC, 2002.

[26] Braudel, F. History and the Social Sciences. 6. ed. Lisboa: Presença, 1990. 